\title{
Barriers to the Implementation of Food Safety and Hygiene Principles (HACCP) in TVET and University Hospitality Schools in Kenya
}

\author{
Dr. Monica A. Wandolo, Prof. Douglas Ndiritu, Dr. Rosemarie Khayiya, Dr. Beatrice W. Mugendi
}

School of Hospitality and Tourism Management of Kenyatta University, Kenya.

\begin{abstract}
The purpose of this study was to assess the barriers to food safety and hygiene principles (HACCP) in TIVET and University hospital schools in Kenya. A total of 671 respondents participated in the study (Comprising 249 from universities, 250 from Institutes of Technology, 64 from Polytechnics and 128 from Technical Institutions). Primary data sources included using structured questionnaires, taking photographs, oral interviews, observation check list and focus group discussions. Secondary sources, on the other hand, involved retrieving information from desk research where journals, books and other relevant literature were obtained. Both descriptive and inferential statistics were used to analyze the quantitative data while content analysis was used to analyze the qualitative data. The analyzed data were presented in terms of graphs and tables. The findings revealed that $31 \%$ of the respondents admitted that there were barriers. Among the barriers were: lack of knowledge (32\%), lack of set standards $(31 \%)$, attitude (31\%), lack of time $(28 \%)$, lack of motivation $(27 \%)$ lack of experience $(26 \%)$, lack of facilities $(23 \%)$ and inadequate equipment $(23 \%)$. The study concluded that various factors such as lack of knowledge, attitude, lack of motivation and inadequate facilities and equipment posed serious threats to effective implementation of proper food safety system (HACCP). It was recommended that HACCP prerequisites related to institutional facilities are put in place and stakeholders trained on adherence to the principles.
\end{abstract}

Key Words: Barriers to food safety and hygiene, Hazard Analysis and Critical Control Point (HACCP)

\section{I: Introduction}

According to a report by World Health Organization (2003), the magnitude of Food-Borne Diseases (FBDs) caused by contaminated food and water significantly contributed to a myriad of health problems. FBDs were said to be on the increase despite adoption of vast measures to curb food-related illnesses. The Centre for Disease Control and Prevention (CDC, 2005) attributed this upward trend to increased multiplication rate of disease-causing microorganisms and exposure to high levels of toxins from industrial effluents. CDC (2005) further added that poor hygiene practices, inadequate cooking, improper holding temperatures, use of contaminated equipment and poor personal hygiene contributed significantly to the spread of FBDs. Though symptoms of FBDs varied from one individual to another or from place to place, common symptoms ranged from mild gastroenteritis to life-threatening neurologic, hepatic, and renal syndromes (Hughes, 2000).

Further reports by CDC (2005) indicated that more than 250 different food-borne diseases have been identified and most of the illnesses are caused by microbial contaminants. Some of the most common disease-causing microbes included Escherichia Coli 0157:H7, Salmonella, Campylobacter and Staphylococcus among others (CDC, 2004). Among these groups of microorganisms, some were capable of mutating and re-emerging as new organisms. This feature, frequently observed in Salmonella enteritidis and Escherichia-coli 0157:H7, interfered with the process of reducing FBDs. In the US, for example, a nationwide survey conducted between 1998 and 1999 by the CDC found that microbiological contamination was the number one cause of FBDs followed closely by chemical contamination. Food-related infections were said to constitute a critical health problem in both developed and developing countries (Dugassa, 2007). Further reports indicated that food- borne illness was a major cause of personal stress, preventable death and avoidable economic burden in USA (Mead, Dunne, Graves, Weidman, Patrick, \& Hunter, 1999). It had also 
been estimated that food-borne diseases causes 76 million illnesses, 325,000 hospitalizations and 5000 deaths each year (Anding, 2001). Additionally, the annual cost of FBDs in terms of pain and suffering, reduced productivity and medical cost is estimated to be between \$10-83billion (Anding, 2001).

Apart from the USA, other developed countries also experienced the burden of FBDs. In Turkey, for instance, a total of 23,010 cases of dysentery were reported in 1997 (Aycikel, 2007). In Emilia-Romagna, a single region in Italy, 1564 episodes of food-borne diseases were reported between 1988 and 2000 (Legnani, 2004). A national survey done by the British government in 2009 revealed that outbreaks of food poisoning had serious financial and social implications (Christopher, 2010). The survey further added that Salmonella alone caused 1939 food-related illnesses (Acheson, 2011). On the same vein, indicated that about one million people suffer from food poisoning every year at an estimated cost of $\$ 1.5$ million annually (Acheson, 2011). Another observation by Rona Ambrose, Minister of Health in Canada (2014), also reported that although Canada boasted of the safest and healthiest food safety systems in the world, the Government was still committed to strengthening food safety by giving tough penalties and cracking down those that did not comply with food safety measures.

In developing countries, particularly in most African countries, a change in socio-economic setting had resulted in multiple food safety challenges (Green, 2003). Green pointed out that between $70 \%$ and $90 \%$ of employees in Africa were in the food trade. These traders were said to significantly influence the prevalence of FBDs in their respective countries. Green (2003) added that availability, distribution and maintenance of adequate supply of portable water and nutritious food were the major challenges to most of these countries. Moreover, inadequate sanitation and physical facilities were said to contribute to lower aesthetic standards, resulting to contaminated food and water (Green, 2003).

According to Dugassa (2007), the burden of food-borne illness in developing countries was significant, and was said to be in a worse condition than developed countries due to inadequate and poorly developed food safety structures and policies. A report by FAO and WHO (2005) indicated that the challenges of food safety in Africa were precipitated by poor food safety systems, lack of systematic surveillance and structural organizations which were viewed as weak and could not protect human health. Besides, there was underdeveloped human resource and insufficient capacity to determine the prevalence and magnitude of the problem. According to Adams (2003), developing countries experienced the challenges of widespread poverty, rapidly growing population and large-scale migration to already overcrowded cities leading to poor sanitary conditions. He further indicated that about 2.6 billion people in developing countries lacked even a simple pit latrine, and about 1.1 billion had no access to portable water. Adams (2003) therefore concluded that food safety was a big challenge due to lack of facilities for hygienic preparation and storage of food.

Kenya, like other countries was not exempted from the burden of FBDs. According to Abegaz (2007), up to $70 \%$ of all diarrhoeal episodes were attributed to ingestion of contaminated food and water. This study viewed training intervention of food handling personnel as a solution not only in Kenya but also in Africa and other developing countries struggling with food safety challenges. It was upon this backdrop that this study aimed at determining the barriers to the implementation of food safety and hygiene principles (HACCP) in TVET and university hospitality schools in Kenya.

\subsection{Problem Statement}

Food poisoning is on the increase as a result of consumption of unwholesome food. Food handling personnel are assumed to be responsible for most illnesses as a result of poor handling behaviour. Angelilo, Vigiani, Rizzo, and Bianco (2000) argued that although food handling personnel played an important role in producing food for consumption, they were likely to contaminate the food by introducing pathogens in the process of preparation, production, processing, distribution and service. Studies by Akonor and Akonor (2013) indicated food safety was a public health problem associated with consumption of food and water, mainly triggered by improper food handling practices. Studies conducted by Mulan and Wong (2006) reported that an estimated 5.4 million Australians got sick annually from eating contaminated food and that up to $20 \%$ of the illnesses were suspected to originate from inappropriate handling behaviour. In fact, the WHO (2007) also recorded that up to $30 \%$ of individuals in developed countries suffered illnesses related to 
consumption of food and water hence pointing out that food safety was a major global catastrophe (WHO, 2007).

Kenya is not an exception. A number of FBDs triggered by improper food handling practices have affected the Kenyan population over the years. Abegaz (2007) noted that the most prevalent diseases in Kenya in the year 2004 alone were typhoid, which affected 643,151 people, dysentery, which affected 600,660, and gastroenteritis, which affected 722,275 people. Abegaz also added that aflatoxin poisoning affected 323 and brucellosis 198, while 68 persons were victims of cholera. Based on the frequency and location of the diseases, the report further indicated that some of the FBDs were seasonal and subsequently, required urgent intervention. Other reports indicated that E.coli alone caused an estimated 73,480 illnesses, leading to 2,168 hospitalizations and 61 deaths annually (Rangel, Sparling, Crowe, Griffin and Swerdlow, 2005).

Globalisation, rapid urbanisation, increase in population and change of eating habits has led to a significant increase in the growth of the food service outlets in Kenya. Despite the economic benefits of these sectors, they are viewed as potential hazards especially when food is not hygienically prepared. There is therefore a critical need to provide adequate training for food handling personnel, to ensure that FBDs caused by improper food handling practices are eradicated. This study identified that in Kenya, food handling practices are taught, but when it comes to practice, the ballgame changes. Accordingly, Mortlock, Peters \& Griffith, (2009) observed that efficacy of training in terms of changing behaviour and attitudes to food safety was questionable. However, Clayton and Griffith, (2004) observed that only knowledgeable trained and skilled employees followed proper procedures when handling food. In essence, if food handling personnel are trained on proper food handling practices, there is likelihood that FBDs will take a decline trend. It is upon this background that this study sought to determine the barriers to the implementation of food safety and hygiene principles (HACCP) in TVET and university hospitality schools in Kenya.

\section{II: Literature Review}

This Section presents the relevant literature on the barrier to the implementation of food safety and hygiene principles (HACCP).

\subsection{Barriers to Food Safety Practices}

Pragl et al., 2007 asserted that food-service establishments were expected to address emerging issues of barriers to food safety practices to narrow the gap between food safety knowledge and practice. Consequently, they argued, food safety training could incorporate strategies that eliminated barriers to proper handling practice in order to improve compliance and reduce the incidence of food-borne related disease outbreak. The report further asserted that training was only valuable if its importance was translated into performance. Transfer of training was viewed as the core issue that linked individual change to an organization's requirements. To realize the difference on food handlers in the organizational performance, Yamnill and McLean (2001) recorded that the transfer of knowledge must be clear to ensure it is translated into practice. Seaman and Eves (2009) gave strength to that argument by adding that the managers had to be on the frontline in training and the management had to support food safety training and reinforce the adoption of safe food handing behaviours. Education and training were expected to enable trainees to perform the given tasks effectively and with understanding. It is on these premises that this study saw the need to cover the three types, which included personal, environmental and food hygiene.

\subsubsection{Personal Hygiene}

Regulation (EC) No 853/2004 stated that "Every person working in a food handling area shall - maintain a high degree of personal cleanliness and wear suitable clean and appropriate protective clothing." Personal hygiene was defined as the maintenance of personal health, particularly by cleanliness (McLauchlin and Little, 2007). Rippington (2008) recorded that personal hygiene was achieved through daily bathing or showering, wearing clean underwear, caring for the hair, mouth, teeth, hands and nails. Green and Selman (2005) reiterated that good hygiene was the foundation for preventing the spread of food-borne illnesses, as human beings were said to be the major source of food contamination. On the same breath, McSwane, Rue and Linton (2005) postulated that if a food handler was not clean, any food handled by dirty hands could contaminate the food with organisms from their gastrointestinal tract. In another observation, Collins (2001) shared the same sentiments and asserted that lack of personal hygiene amongst food handlers were likely to 
contribute to food-borne illnesses. Sneed et al. (2004), in addition, argued that good personal hygiene prevented incidences of cross-contamination to a reasonable level. The same was noted by Angellilo, Viggiani, Rizzo, and Bianco (2000) who observed that personal hygiene could be a source of cross contamination. Elson (2006) cited personal hygiene of food handlers as the most important aspect in the prevention of food poisoning.

According to (FAO/WHO, 2006), components of personal hygiene included the cleanliness of the hands and body and maintaining good personal cleanliness, wearing clean and appropriate uniforms, and by following hygienic sanitary habits in addition to maintaining good health and reporting any ill health to medical personnel. On the same note, Clayton et al., (2002) reiterated that inappropriate food handling practices alone led to $97.0 \%$ of food-borne diseases. Pragle, et al., 2007) recorded that food handling played an important role in the safety of the clients and therefore, the managers were expected to take an active "coaching-style" approach to promote hand washing. In a similar study on food handlers' perspectives of barriers to hand washing, participants stated that they wanted "hands-on" hand washing training to be included in pre and post- training as an element of motivation to food handlers in sustaining safe handling practices learnt during training (Seaman and Eves, 2009).

\section{Hand Washing}

Hand washing was said to be the most critical aspect of personal hygiene. Proper hand washing was very important in the prevention of transfer of staphylococcus from one surface area to another. Green (2006) noted that food worker hand washing practice was critical because pathogens from the hands to food were a major contributing factor to food-borne illnesses. Many food handlers failed to wash their hands as required especially where hand washbasins were not provided. Though hand washing took only twenty seconds, staff rarely practiced it. There was need to train in the five steps of washing hands: wetting, applying soap, scrubbing hands and arms for 10 to 15 seconds, rinsing thoroughly, then drying hands using disposable towels or hot air dryers. The Food Standard Agency (2006) stipulated six steps of hand washing procedure that took the following sequence:

Step 1: Wet hands thoroughly under warm running water and squirt liquid soap onto the palm of one hand.

Step 2: Rub hands together to make a good lather.

Step 3: Rub the palm of one hand along the back of the other and along the fingers. Repeat with the other hand.

Step 4: Rub in between each finger on both hands and around the thumbs, fingertips and nails.

Step 5: Rinse off soap thoroughly with clean running water.

Step 6: Dry hands thoroughly using a paper towel or a hand dryer. Turn off tap with the towel and dispose of the towel or turn off the tap using an elbow.

Another premise in support of proper hand washing came from The National Restaurant Association Education Foundation (NRAEF, 2004), which reiterated that hands were to be washed under running water of at least $100^{\circ} \mathrm{F}$ and be scrubbed for at least 20 seconds then dried under single use paper towels. Elson (2006) recorded that food handlers were to be trained to wash their hands before they started work, during preparation processes particularly after every procedure in operation. He added that nails were to be kept short, nail polish was not be worn and artificial nails were not be used. Elson (2006) continued to say that all cuts and wounds on the hands were to be covered and in case one had burns, boils, sore skin infection or infected wounds, one was not to work.

According to Angellilo et al., (2000), hands had to be washed before wearing gloves and more importantly, gloves were not be used before hand washing. The gloves were to be made from safe, durable and easy to clean materials. Disposable gloves and finger cots had to be worn on bandaged wounds and hands. Angellilo et al. (2000) also observed that food-handling personnel had to report health problems to the manager of the establishment before working.

\section{Other Important Personal Hygiene Practices}

Other personal hygiene practices, according to Richard (2006) included wearing a hat or other hair restraints, wearing clean clothing daily, removing aprons when leaving food preparation areas, removing 
jewellery from hands and arms and wearing appropriate shoes. In addition, policies regarding eating, drinking, smoking and chewing gums and tobacco, sneezing, coughing, using a tissue, taking out garbage or touching anything that could contaminate hands such as un-sanitized equipment or work surfaces had to be observed (Richard, 2006). Richard further argued that in case food was to be tasted during preparation; it had to be placed in a separate dish and tasted using a spoon and a saucer.

In other words, as Richard so ardently put it, good personal hygiene was a critical protective measure against contamination and food-borne illnesses (Richard, 2006). The NRAEF (2004) synopsized the whole matter when they recorded that the success of personal hygiene depended on a well-trained food handler who had acquired knowledge, skills and attitude necessary for keeping food safe (NRAEF, 2004).

\subsubsection{Environmental Hygiene}

According to European Union Food Safety Standards EC No.178/2002 regulation, food establishment had to comply with legal requirements covering constructions. The premises had to be designed and constructed in ways that prevented contamination and access to pests.

It considered the layout of the kitchen, equipment and other facilities in relation to hygiene in and around the food production premises. Becker (2003) defined a food premise as the building, structure, caravan, vehicle, or stand used for storage, preparation and service of food. It also included areas where equipment were washed and stored, lockers, washrooms and garbage disposal areas. Fosket and Ceserani (2007) defined the term food premises to comprise the kitchen (where ingredients were brought, prepared and cooked according to the menu of the day), the restaurant (where food was served and consumed), and the storage area (where food materials were ordered, stored and issued for production) The FAO, HACCP board of experts (2002), the Kenya Public Health Act, Cap 242 of 1986; and FSA, (2006) advised that food premises had to be designed properly to ease cleaning.

\section{Cleanliness of Premises}

The FSA (2000) particularly recommended that all sections of the premises where food-related activities were carried out had to be kept clean, in good repair and well maintained. Specifically, kitchens and restaurants as the major areas of operations where food was prepared, had to be designed to separate "low risk" (uncooked product) from "high risk" (cooked product) areas. The premises were required to have adequate space, hygiene, design and construction, appropriate location and provision of adequate facilities to control the hazards. Food premises design as explained by Birchfield (2008), referred to the entire facility while the layout involved a consideration of each small unit or workspace in the facility. Knowles (2002) and Mohini (2004) recorded that the size of the facility was supposed to be determined by the menu to be served and the workload expected, as well as the type of establishment and the purpose for its intended use. Besides, the facility was required to be large enough to accommodate all materials and equipment required, as well as to allow free movement during operation.

\section{Location of Workshops}

Workshops had to be ideally located for the proper practice of food hygiene. Basics such as adequate lighting, ventilation and portable water supply were essential (Paster, 2007). Hoffman (2007) argued that the surrounding area was not supposed to be potential breeding ground for mice, flies or harmful insects. Sanitary facilities such as hand wash basins, and rest rooms used by staff had to be conveniently located and the number adequate enough to serve the anticipated number of staff. Moreover, shower and changing rooms were to be made available if hygiene was to be taken into consideration. Hoffman further argued that facilities of handling, transporting and carrying foodstuff on the way to establishments had to be properly cleaned, and the route used for waste disposal (refuse point) had to be well maintained. He added that refuse was not to be carried through the kitchen or dining rooms (Hoffman, 2007).

\section{Size, Nature and Layout of Premises}

According to the FAO/WHO (2007), food storage premises needed to be cool and dry. Walls needed to be built with damp proof material. Working premises needed to be large enough to allow employees to carry out their work comfortably without congestion on traffic lines. Working tables were not to be crowded and 
the queuing for the use of sinks was to be avoided. They further recorded that large gangs allowed free movement and good working environment and sufficient tables and shelf space needed to be available to allow used and unused utensils to be kept apart from each other and from food preparation areas (FAO/WHO, 2007). Paster (2007) corroborated that a good design was needed to ensure that equipment and facilities were constructed in a way that contamination was minimized, by ensuring that premises were located away from environmental pollution, flooding or pest infestations. Proper sanitation and maintenance of premises were recorded as important to permit continuous and effective control of food hazards, pests and other agents likely to contaminate food (FAO/WHO, 2007).

The objective of good premises design also required that surfaces and materials, particularly those that came into contact with food were non-toxic, durable, and easy to maintain and clean. Walls and floors were to be made of impervious non-toxic materials and suitable materials for design to ensure an effective protection against pest, adequate supply of portable water, and other sanitary facilities. Also, monitored parts of the premises had to be sanitized and pest control procedures undertaken to prevent access or infestation (FSA, 2006). The area surrounding the location of the workshop was considered important in view of airborne contaminants that could have posed a risk to the food business. Besides, odors emanating from the surrounding areas and infestation with pests were reported as likely to lower the standards of operation (CDC, 2008) if the facility was located in a poor environment.

Layout of kitchen was required to consider storage areas with goods' entrance clearly separated from customers' entrance. Stores arrangements were required to allow cool, well-ventilated and large enough vegetable storage rooms to allow for orderly storage. Stores were required to have a good drainage system to exit water. In addition, FAO (2005) recommended that store walls and partitions had to be made with smooth surfaces that would ease cleaning and be treated with residual insecticides to prevent pest infestations. Besides, the storerooms were to be well lit, ventilated and where possible the doors had to be fitted with glass panel. Cabinets were to comply with the standard specification and allow the rotation of stock.

When planning for a kitchen, according to Griffin (2007), chief factors to be considered included the flow of work, the nature of various operations and the position of windows, doors and drainage. Kitchens were not to be used as thoroughfare to other parts of the building. The floors were to be constructed in such a way as to allow adequate drainage and cleaning. The windows were required to be easy to clean, constructed to minimize built-up dirt, while at the same time fitted with cleanable insect proof screens. The kitchen was required to have adequate natural and artificial lighting (Griffin, 2007).

Ceilings and overhead fixtures such as extraction hoods needed to be constructed to minimize the built-up of dirt, condensation of steam and the shedding of food particles. Built-in cupboards and other fixed kitchen units needed to be arranged to allow enough spacing. Free standing equipment were to be used as they were much more hygienic. Paster (2007) further recorded the several forms of kitchen organizations that existed, with the most common ones being the U- shape, L-shape and island arrangements. Paster (2007) asserted that an island layout made it easy to maintain and clean the equipment. Equipment may be fixed, wall mounted or mobile. McLauchlin and Little (2007) recommended that for ease of cleaning, equipment had to be accessible or mobile. If fixed, the equipment may have a space of at least $300 \mathrm{~mm}$ behind them, as moveable equipment and worktops facilitated cleaning. Island grouping of cooking appliances referred to an arrangement whereby all the cooking equipment were arranged in the middle of the kitchen, sometimes back-to-back and fitted with splash backs. McLauchlin and Little (2007) cited this system as convenient for the extraction of steam and odours.

Griffin (2007) argued that ideally, a good plan needed to have working tables against the walls between the sinks and the ovens, stores, mixing machines and ranges in the centre of the room. Working tables needed to be movable for easy cleaning. He added that cooking stoves and ranges required a canopy and exhaust fan system of ventilation (hoods) to draw off the fumes, and recommended small extract fans to draw steam and odours from small cooking ranges over a filter pad (Griffin, 2007). Griffin further added that working surfaces coming into direct contact with food needed to be made of smooth non - absorbent durable 
materials that were easy to maintain and sterilize. Alli (2004) reiterated that design and layout of a food premise had to be constructed in such a way that it permitted good hygienic practices. These hygienic practices needed to be extended beyond the food itself to the environment in which the food was prepared to prevent contamination. The accumulation of dirt on surfaces, floors, walls and ceilings of food storage, preparation, production and service areas undermined food hygiene, hence the requirement for the cleaning and disinfection of floors, walls, ceilings and other surfaces.

Sanitary facilities near work areas provided good personal hygiene, reduced loss of productivity and allowed proper supervision of food handler, asserted (Mc Swane, Rue \& Linton, 2000). According to the Kenya Food, Drugs and Chemical Substances Act, cap254 of 1992 Regulation 11(K), adequate suitable and conveniently located change rooms, toilets and ablution facilities needed to be provided in all food establishments. (Regulation 8(2) of the Kenya building code section 150-166 and section 190 also stated that facilities needed to be well ventilated, well lit and were not to be opened directly onto food preparation areas.

\subsubsection{Waste Disposal}

Waste if not properly removed would potentially result into contamination of food, equipment and water and also attract breeding of pests. According to the Kenya Food, Drugs and Chemical Substances Act, cap254 of 1992, Regulation 7 (11), waste needed to be disposed in designated containers with covers for temporary collection of waste and garbage. The containers were to be properly identified and were to be made of durable impervious materials. Besides, the containers needed to be kept in sanitary condition. Cap 242 of 1972 sections 127 and 128 of Kenyan regulation further stated that no leakage from the waste containers was to be allowed, and that the containers needed to be well maintained so that they would not become sources of contamination or pest infestations.

During the course of preparation, waste products were recorded to be generated in the store, kitchen and restaurant. These waste products were either organic (waste food, used cooking oils) or inorganic (papers, plastics, cans). These waste products became breeding grounds for microbes and served as potential sources of contamination when allowed to accumulate, or became centres of attraction for rodents, pests and flies if not disposed of properly. McLauchlin and Little, (2007) recommended immediate waste disposal by sorting and destroying according to type. According to Blanch (2003), the method of waste disposal needed to be in line with the recommendation of the public health officers. Fosket and Ceserani (2007) also maintained that accidents, contamination, pest infestation, unpleasant odours, fire hazard and pollution needed to be prevented with correct clearing and handling of wastes.

According to Fosket and Ceserani (2007) and McLauchlin and Little (2007), food and other waste containers needed to be closed, cleaned and disinfected, and all storage and waste disposal facilities needed to be designed and built with pest proof materials to allow easy cleaning. Pest infestations were recorded to occur as a result of inadequate cleaning, poor building maintenance, as well as suppliers' deliveries. Food pests included rodents (such as rats, mice, squirrels), birds and insects (such as cockroaches, flies, ants and wasps). Pests in food production areas were not only unsightly and repugnant, they also caused damage to food and building. According to Blanch (2003) and McLauchlin and Little (2007), pests contaminated food products by their bodies or body parts, fur, eggs and droppings and were a potential source of infection. Infestation of pests as suggested by McLauchlin and Little (2007); Blanch (2003); Fosket and Ceserani (2007) was controlled by denying the pests access, harbor, warmth, sources of food and water in the premises. This was achieved through regular inspection of the premises, cleaning of the workshop, immediate cleaning of spillage and food particles from the kitchen surfaces.

\subsubsection{Wash - Up Areas}

Where possible, crockery, cutlery, and all dirt articles were to be taken to the washing-up room, sorted into various categories and sizes and stacked (FSS, 2007). Wash- up areas in any operation was a very important section although it was regarded as a menial task. During wash-up, Paster (2005) asserted that food residues needed to be scraped or tipped off into refuse containers. The aim of scraping was to keep the washing water as free as possible from food particles and germs. A three-sink method of washing -up was appropriate where the first sink with hot soapy water was used for washing, the second for rinsing with plain warm 
water and the third with water heated to a temperature of about $60^{\circ} \mathrm{C}\left(140^{\circ} \mathrm{F}\right)$. The utensils were suitably arranged in wire baskets for immersion in the sterilizing rinse. No detergents or chemicals were to be added to the sterilizing sink but the water was to be maintained at a temperature of not less than $77^{\circ} \mathrm{C}\left(170^{\circ} \mathrm{F}\right)$. The utensils were to be left in the hot water for at least two minutes. The hot temperature would also air - dry the utensils almost instantaneously. No further drying by clothe was recommended especially for crockery but could have been useful for cutlery (Paster, 2005).

Paster (2007) argued that thorough cleaning and effective sterilization of the utensils used in preparation and service was the manager's obligation to his/her customers. Sometimes dirty utensils were piled and allowed to accumulate until the end of the day, which created a possibility of a guest being served with dirty crockery or cutlery and particularly with cups stained with lipstick or over-running from previous fillings (Paster, 2007). To ensure wash - up was efficiently done, the staff were supposed to keep their hands meticulously clean, with no open wounds or sores on their hands and arms so as to avoid contaminating the utensils. Though most institutions washed their utensils manually by hands, some few institutions had washing machines. Whichever the methods applied, washing up should to be done promptly to prevent the accumulation of dirty utensils, which posed a risk of dangerous germs multiplying in the food residues. Efficient wash-up required suitable equipment to be followed by proper storage in a clean store. Indeed the rush hour practice of rinsing and washing in a basin of tepid water and washing a plate by holding it under cold water jet and then wiping with a tea towel before placing it before a customer should not be tolerated in any establishment as practised in most of the TVET and hospitality restaurants.

Paster (2007) went on to argue that where chemical sterilizers were used, the usability, cost and availability were to be considered. The manufacturers' instructions needed to be carefully followed. The basin wash practised by many institutions was usually a greasy job and required ample supplies of clean and very hot water. Pan washing was done by hand and therefore, the use of special detergent and where possible scouring powder was recommended (Paster, 2007).

\subsubsection{Water supply}

Water being an essential commodity in the food industry used extensively for drinking, cleaning and preparing food, washing up, washing hands, equipment, utensils, containers, clothes, among others, it was imperative that the food premises got adequate supply of portable water for all the operations in the kitchens. There was also need for adequate supply of drinking water, and all ice consumed in food premises was supposed to be made from drinking water. Like food, water was a major source of contamination and infection leading to water-related diseases such as diarrhoea, typhoid, cholera and salmonella typhimurium Water used for washing food eventually became part of the food; therefore, it was necessary to ensure that contaminated water was not used in the kitchen. The sources of water used in food preparation determined the quality and safety of food prepared. According to Knowles (2002), water acted as a vehicle for a number of micro-organisms other than those which caused typical food poisoning. Water contamination needed to be controlled through boiling for small scale use and chlorination for large scale use. It was expected that all food establishments would source their water from government regulated main water pipes but where a food premises could not access the main drinking water supply, private water supply needed to be arranged. The sources of private water supply ranged from deep boreholes to springs, wells and harvesting of the rain water (McLauchlin \& Little, 2007). It was advised that all sources of water, whether private or from the mains needed to be protected from being contaminated by sewage caused by poor drainage system.

\section{III: Methodology}

Descriptive cross sectional survey design was used in the study. The design combined both qualitative and quantitative data collection and analysis techniques. Quantitative data was derived from questionnaires while qualitative data was generated from interview schedules. The design was therefore appropriate for the study since this study was interested in establishing the facts as they are in relation to food and hygiene practices in training institutions. The study was carried out in TVET institutions offering diploma programs and university hospitality schools offering degree programs in Kenya. The TVET institutions included Polytechnics, Institutes of Science and Technology and Technical Training Institutions (TTIs). There were 
over 44 TVET institutions and over 10 university hospitality schools in Kenya that offered courses in food and beverage production and service. The inclusion criteria consisted of all third year students in TVET institutions who were almost graduating, and third year students from Universities who had covered three quarters of the course-work. First and Second years were excluded from the study as they had not had enough exposure in food production or food and beverage service. Heads of Departments of these courses were also included, as they represented their various institutions. A total of 671 respondents participated in the study (Comprising 249 from universities, 250 from Institutes of Technology, 64 from Polytechnics and 128 from Technical Institutions).

In the selection of respondents, both probability and purposive sampling techniques were used. Probability sampling technique was used in selection of student-respondents. In this case, each target student-respondent was pre-assigned some chance of being included in the sample. This technique was used since it minimized biases in sample selection. As one method of probability sampling technique, lottery method was used to identify specific sample units. This was done using identical cards where numbers were written and cards drawn at random. Population unit whose identification number corresponded to a drawn card was selected. This procedure was repeated for all the sample units. On the other hand, purposive sampling technique was used in the selection of staff-respondents. This technique was used since it facilitated the provision of focused information, besides being able to save time and money. Both primary and secondary data were used in the study. Primary data sources included using structured questionnaires, taking photographs, oral interviews, direct observation and focus group discussions. Secondary sources, on the other hand, involved retrieving information from desk research where journals, books and other relevant literature were obtained. Questionnaires were used to collect data from students and lecturers while interview schedules were used to collect data from departmental heads. Both descriptive and inferential statistics were used to analyze the quantitative data while content analysis was used to analyze the qualitative data. The analyzed data were presented in terms of graphs and tables.

\section{Findings Of The Study}

This section presents the findings of the study on the barriers to the implementation of food safety and hygiene principles (HACCP) in TIVET and University hospital schools in Kenya.

\subsection{Barriers to food safety and hygiene practices in TVET and University hospitality institutions}

In this section, the researcher focused on possible barriers to food safety and hygiene practices. Specific barriers included lack of motivation, lack of proper set standards, attitude of the staff and students, lack of knowledge, time, sanitary facilities, inadequate equipment and finance. Ratings of the effect of these factors were based on a Five-Point Likert Scale, which was 1-Very large extent, 2-Large extent, 3-Neutral, 4-Small extent and 5-Not used at all. Figure 1 summarized this finding. 


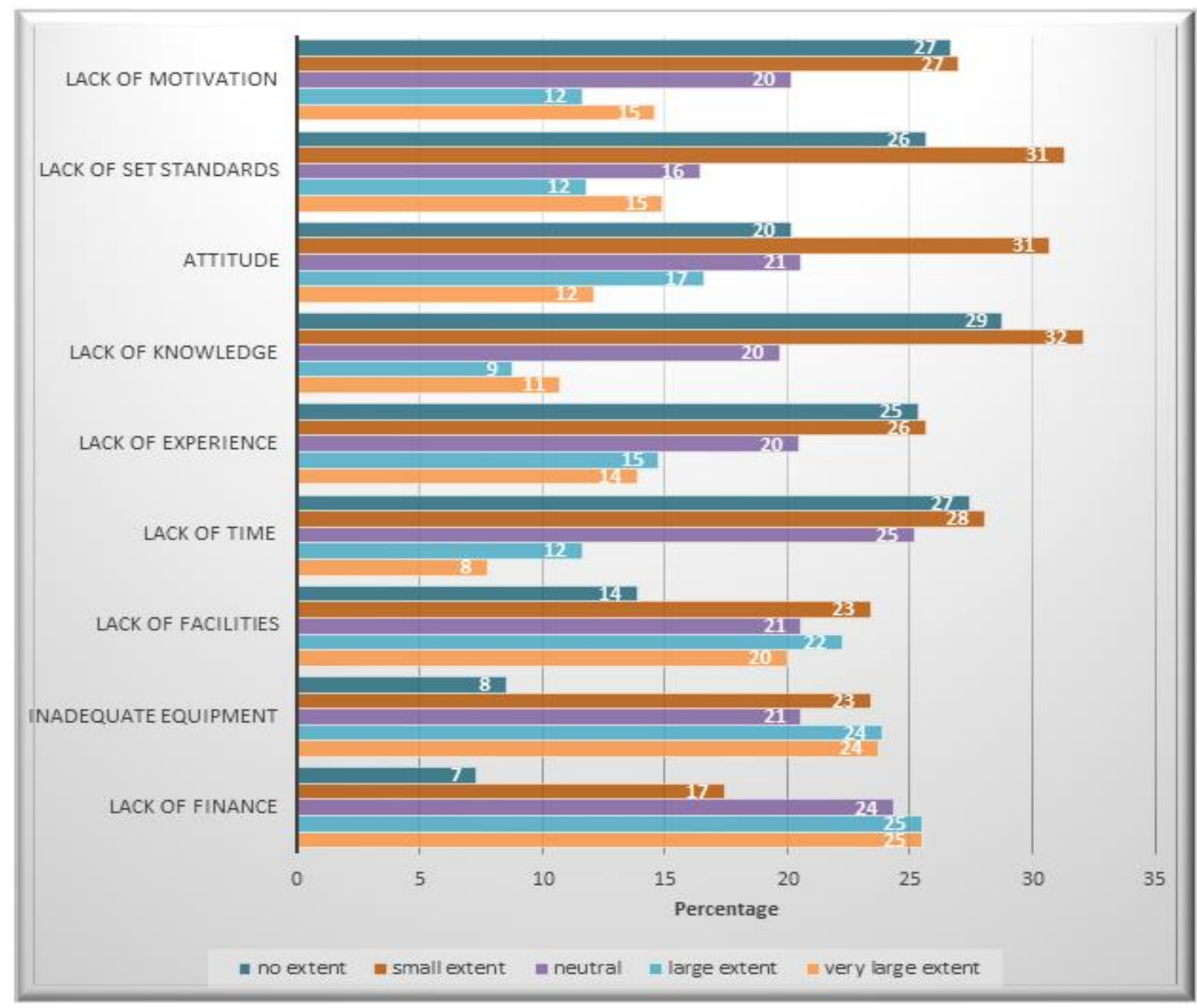

Figure 1: Barriers to Food Safety and Hygiene Practices

From Figure 1, though all the previously stated factors were threats to food safety and hygiene practices, some factors posed more threats to proper food safety and hygiene practices. Such factors included lack of facilities, inadequate equipment and lack of finance. The study further sought to know the extent to which the three factors posed threat(s) to the two institution categories. The findings were summarized as shown in Figure 2 .

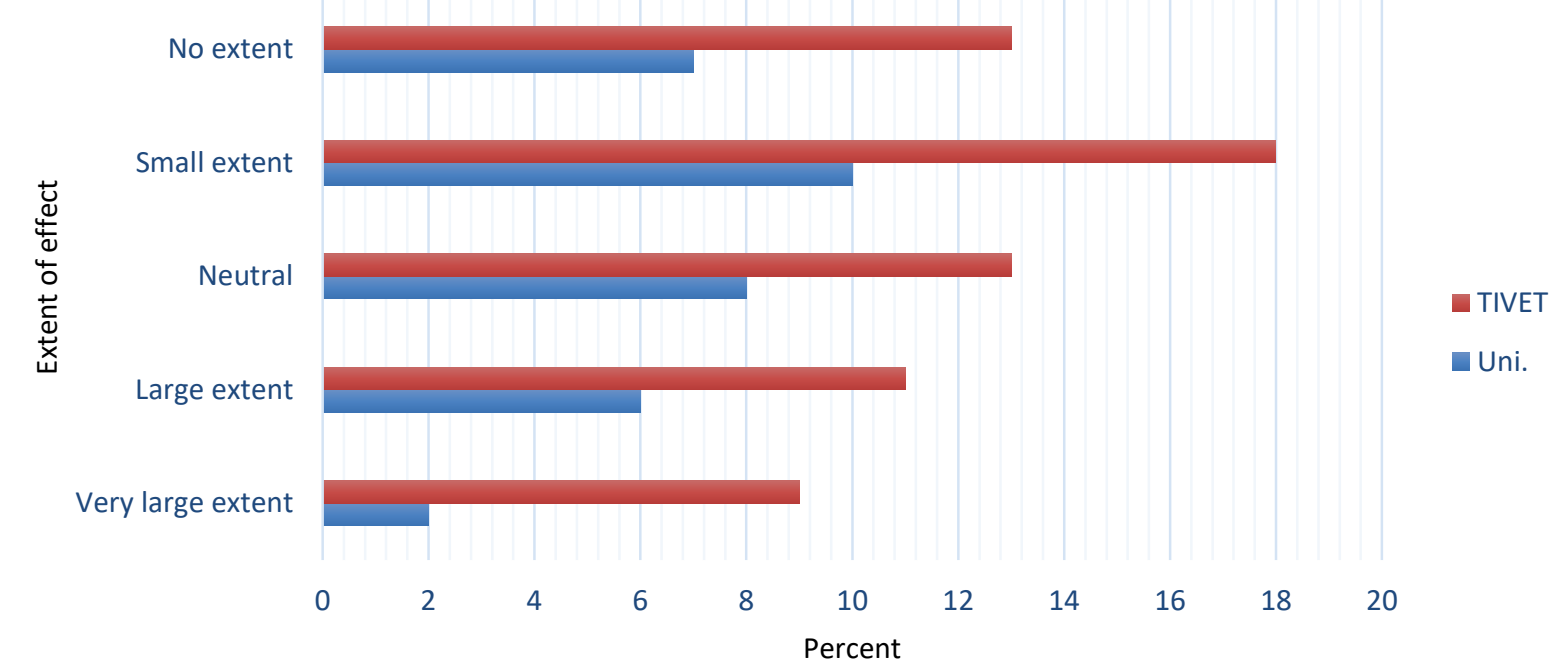

Figure 2:- Extents of Effects of Barriers to Food Safety and Hygiene Practices 
Figure 2 illustrated that from all extent categories, responses for TVET were higher than those of University hospitality schools. Noted, also was that there was a slight skewness towards the Large Extent side in both institution categories. This can be seen as shown in Figure 3.

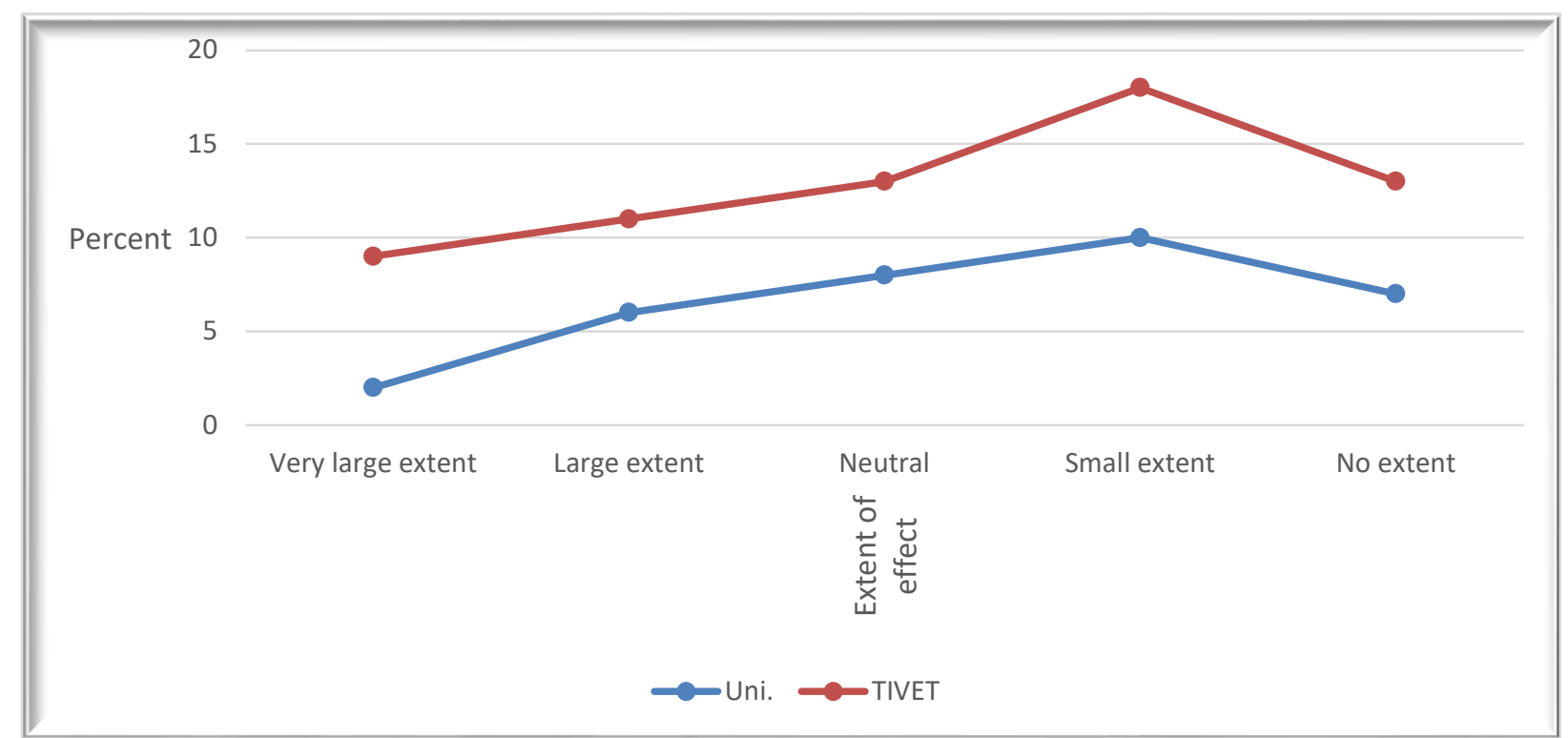

Figure 3:- Line Graph Showing Extents of Effects of Barriers to Food Safety and Hygiene Practices

Figure 3 showed that the distribution of the responses in the extents of effects of the identified barriers to food safety and hygiene practices was almost similar in the two institution categories. It was also observed that even though most respondents $(48 \%)$ agreed that the factors had minimal effects, significant proportion $(28 \%)$ did, however, respond that the identified factors had negative effects to a large extent.

As noted by Panisello and Quantic (2001), focus on barriers to food safety and hygiene practices was a vital component of attaining regulations provided by the HACCP system. In addition to inadequate finance and facilities, Panisello and Quantic (2001) observed that improper learning schedules, incompetent food handlers, poor motivation and cultural differences were among serious factors that thwarted proper food safety and hygiene practices. The report further revealed that there were many risks of food safety due to industrialization and mass food production due to longer and more complex food chains involved. Besides, the fast growth of eating out habits was cited as a major cause of food safety problems and impediments to HACCP.

A study conducted by Lee and Lee (2005) in Seoul Women University in Korea found that the most important drive promoting implementation of HACCP was implementation in supplier facilities. Other observed challenges included lack of training methodology, incompetent teaching staff and limited facilities/equipment. The study suggested that more investments on facilities/equipment were needed for food safety improvement and successful implementations in schools and food service out-lets. The study also asserted that proper training of employees and availability of facilities enabled the employees to monitor Critical Control Points and take corrective actions. Another study by Mitchel, Fraser and Beacon (2007) postulated that job stress, work pressure and high placed environment contributed to poor food safety at the work-place. Moreover, the study observed that catering work-site was quite demanding and led to a stressful fast - paced environment making it vulnerable to food safety malpractice.

\subsection{Testing of Hypothesis: Independent T-Test for Differences in Barriers to Food Safety and Hygiene Practices}

In examining whether the barriers were similar in the two categories of the institutions, the researcher used independent T-test. This test was used to test hypothesis, which was formulated as

$\mathrm{H}_{01}$ There are no barriers to food safety and hygiene practices in TIVET Institutions and University hospitality schools. 
Similar to the previous t-tests, the test was done at $5 \%$ level of significance and the output summarized as shown in Table 1.

\section{Table 1:- Independent T-Test for Differences in Barriers to Food Safety and Hygiene Practices}

\begin{tabular}{|c|c|c|c|}
\hline & T & df & Sig. (2-tailed) \\
\hline Universities - TVET & 14.643 & 1 & .012 \\
\hline
\end{tabular}

In Table 1 , the $\mathrm{p}$-value $(=0.012)$ was less than 0.05 ( $p$ value $<0.05)$. Based on this finding, the formulated null hypothesis was rejected and consequently, a conclusion that there were significant differences in barriers to food safety and hygiene practices in the two institutional categories. This finding implied that the barriers to implementation of HACCP system varied from one institution to another. This implied that the allocation and utilisation of resources in the two categories of the institutions are prioritised differently.

\section{Summary Of The Findings Of The Study}

The purpose of this study was to exploring factors that hampered the implementation of an effective food safety system (HACCP). Consequently, the factors were grouped into three major categories, namely behavioural, psychological and knowledge/expertise barriers. Responses indicated that only $31 \%$ admitted that there were barriers. On the other hand, a fairly large portion of respondents (41\%) said that the effects are very low. Among the barriers were: lack of knowledge (32\%), lack of set standards (31\%), attitude $(31 \%)$, lack of time (28\%), lack of motivation (27\%) lack of experience (26\%), lack of facilities $(23 \%)$ and inadequate equipment $(23 \%)$.

\section{Conclusions}

The study concluded that various factors such as lack of knowledge, attitude, lack of motivation and inadequate facilities and equipment posed serious threats to effective implementation of proper food safety system (HACCP).

\section{Recommendations}

The study recommended HACCP prerequisites related to institutional facilities are put in place and stakeholders trained on adherence to the principles.

\section{References}

[1] Abegaz, M. (2007). Trade capacity building in agro-industry products for the establishment and proof of compliance with international market requirements. UNIDO, Vienna 3, 6-9.

[2] Acheson, D. (2011). Slides on food safety and legislation. Food Journal 102(6), 145-156. In Food Safety Modernization Act.

[3] Adams, M., \& Mortajemi, Y. (2003). African Cities (Abstract). Bulletin on Food Safety for Health Workers, Geneva, Switzerland. WHO, 21-22.

[4] Akonor, P. T., \& Akonor, M. A. (2013). Food Safety Knowledge: The case of Domestic Food Handlers in Ghana 3(3), 99-110.

[5] Anding, D. J. (2001). Self- reported changes in food safety behaviours among the food service employees: Impact of a retail food Safety education programme. Journal of Food Safety Science Education, 6, 72-76.

[6] Angelillo, N. M., Vigiani, L. Rizzo, A. B. (2000). Food handlers and food borne diseases. Knowledge attitude and reported behaviour in Italy. Journal of food pretection, 63 (3), 381 - 385.

[7] CDC (2004). Emerging Infectious Diseases Journal 18(3).

[8] CDC (2005). Foodborne illnesses. International Food Safety Consultancy.

[9] Clayton, D. A., \& Griffith, C. J. (2004). Observation of food safety practices in catering using rotational analysis. British Food Journal 106(3), 211-227.

[10] Clayton, D. A., Griffith, C. J., Price, P. \& Peters, A. C. (2002). Food handlers' beliefs and selfreported practices. International Journal of Environmental Health Research, 12, 25-39.

[11] Collins, S. J., Lawson, V. A., Masters, C. L. (2004). Transmissible Spongioform Encephalophies. Lancet 363, 51-61. 
[12] FAO/WHO (2005). Regional Conference of Food Safety for Africa. Harare, Zimbabwe 2005.

[13] FAO/WHO (2006). Guidance to Governments on the application on HACCP in small and /or less developed business. FAO London.

[14] Food Standards Agency FSA (2006). Guidance on Allergen Management and Consumer Information. London: Operating clean as you go. Food Hygiene (England) Regulations 2006 (www.food.gov.uk).

[15] Green, L. R. (2003). Behavioural sciences and food safety. Journal of environmental Health, 71(2) 47-49.

[16] Knowles, T. (2002). Trends in food safety: Implications for European hotels. International Journal of Contemporary Hospitality Management, 13(4), 176 - 182.

[17] Lee, K. E., \& Lee, L. T. (2005). Department of food nutrition, Adong National University Korea. Journal Korean Diet Association 2005, 179-189

[18] Legnani, P. (2004). Hygiene control of mass catering establishment. Microbiological monitoring of food and equipment. Food Control,15, 205-211.

[19] Mc Lauchlin, J., Grank, K.A., \& Little, C. L. (2006). Foodborne botulism in U. K. Journal of Public Health 28, 337-342.

[20] Mc Swane, D., Rue, N., \& Linton, R. (2005) Mc Swane, D., Rue, N., \& Linton, R. (2003). Essentials of food safety and sanitation. ( $3^{\text {rd }}$ Ed.). New Jersey: Pearson Education.

[21] Mitchell, R. E., Fraser, A. M. \& Bearon, L. B. (2007). Preventing food-borne illness in food service establishment: Broadening the framework for intervention and research on safe food handling behaviours. International of Environmental Health Research, 17 (1), 9 - 24.

[22] Mortlock, M. P., Peters, A. C., \& Griffith, C. (2009). A National Survey of Food Hygiene Training and qualification levels in the U. K. Food Industry. International Journal of Environmental Health 10, 111-123.

[23] Panisello, P. J., Quintic, P.C., and Knowles, M. J. (1999). Towards the implantation of HACCP: Results of a U.K. Regional survey. Food control 10(2), 87 - 98.

[24] Pragle, A. S., Harding, A. K., \& Mack, J. C. (2007). Food workers' perspective on hand washing behaviours and barriers in the restaurant environment. Journal of Environmental Health. 69(10), 2732.

[25] Rangel J. M., Sparling, P. H., Crowe, C., Griffin, P. M., \& Swerdlow, D. (2005). Epidemiology of Escherichia Coli.

[26] Seaman, P., \& Eves, A. (2009). Perceptions of hygiene training amongst food handlers, managers and training providers - A qualitative study. Food Control, July, 21(7), 1037-1041. Guildford Surrey: School of Management, University of Surrey.

[27] Seaman, P., \& Eves, A. (2009). Perceptions of hygiene training amongst food handlers, managers and training providers - A qualitative study. Food Control, July, 21(7), 1037-1041. Guildford Surrey: School of Management, University of Surrey.

[28] Sneed, J., Strohbehn, C. V., \& Gilmore, S. A. (2004). Food Safety Practices and readiness to implement HACCP programs in assisted - living facilities in Iowa. Journal of the American Dietetic Association, 104,1678-1683.

[29] WHO (2003). Evaluation of programmes to ensure food safety, guiding principles. Geneva: Switzerland.

[30] WHO (2007). Food Safety and Food-borne Illness. Fact Sheet 237, www.who.int/mediacentre/factsheets/fs237/en/www.who.int/entity/foodsafety/publication/consumer. 